\title{
Empreendimentos comerciais e a "questão indígena" nos sertões de Minas Gerais (1847-1860)
}

\author{
Weder Ferreira da Silva*
}

\begin{abstract}
Resumo: A Companhia do Mucuri, fundada em 1847 pelo renomado político liberal Teófilo Benedito Ottoni, foi criada em um período de intensa atividade comercial e financeira no Brasil Imperial. Para colocar em prática o ambicioso projeto de comércio e navegação a vapor que interligaria a província de Minas à praça comercial do Rio de Janeiro, o diretor da Companhia empreendeu a conquista de uma região até então habitada pelos temidos índios botocudo. $\mathrm{O}$ presente trabalho pretende abordar as estratégias de cooptação do apoio da população autóctone para o empreendimento capitalista. Pretendemos destacar ainda as ambivalências do processo de assimilação das populações indígenas e sua interface com a dilatação das fronteiras e da modernização do Brasil do século XIX.

Palavras-Chave: Negócios; Colonização; Questão Indígena
\end{abstract}

\begin{abstract}
The Mucuri Company, founded in 1847 by renowned liberal political Teófilo Benedito Ottoni, was established in a period of intense commercial and financial Imperial Brazil. Teófilo Ottoni undertook the conquest of a region inhabited by the Indians feared Botocudo, aiming at putting into practice the ambitious project of steam navigation and commerce. For this purpose intended to link province of Minas Gerais to commercial center from Rio de Janeiro. This paper aims to discuss strategies for co-opting support of the local population for the commercial project. We also intend to highlight the ambivalence of the process of assimilation of indigenous peoples and their interface with frontier expansion and modernization of the nineteenth-century Brazil.
\end{abstract}

Keywords: Business; Colonization; Indigenous Issues

\section{Introdução}

O político liberal Teófilo Benedito Ottoni destacou-se no cenário nacional não apenas pela sua atuação decisiva e conturbada nas questões políticas do Império. Ottoni também esteve à frente de um dos empreendimentos comerciais mais polêmicos e fascinantes do Brasil imperial. A Companhia do Mucuri, dirigida por Ottoni entre 1847 e 1863 atuou em projetos pioneiros na construção de rodovias modernas do Império, atraindo para o interior dos sertões de Minas Gerais imigrantes de diversas nacionalidades. Para tanto, Teófilo Ottoni conseguiu atrair em torno de si boa parte da elite econômica de Minas e do Rio de Janeiro. Sua companhia de comércio e seus empreendimentos no vale do rio Mucuri ganhou as páginas de periódicos como a Revista do Instituto Histórico e Geográfico Brasileiro (IHGB). A empresa destacou-se

\footnotetext{
* Doutorando do Programa de Pós-Graduação em História Social da UFRJ. Mestre em História pela Universidade Federal de Ouro Preto. wedhistoria@yahoo.com.br
} 
também por ocupar as páginas de diversos jornais da corte, como o notável Jornal do Commercio. A partir de 1847, a experiência de ocupação do vale do Mucuri mostrou-se um capítulo importante da história da conquista e assimilação das populações indígenas e do controle de seu território. Daí a importância de se analisar as estratégias utilizadas por Teófilo Ottoni na cooptação do apoio da população autóctone para o empreendimento capitalista.

A história da Companhia do Mucuri foi bastante documentada em sua época. A Notícia Sobre os Selvagens do Mucuri - publicada por Teófilo Ottoni na Revista do IHGB em 1858 - é de todos os documentos o mais rico em detalhes sobre o processo de assimilação da população indígena daquela região. A maior parte deste relato foi transcrito de um ofício remetido por Ottoni ao presidente da província de Minas Gerais em 1853 (ARAUJO,1998). Por ter sido produzida pelo maior interessado na conquista das terras do Mucuri, muitas vezes o seu autor apresenta-se como portador do lume da civilização que deveria extirpar a barbárie personificada na própria população indígena.

Fruto da experiência que desenvolveu como diretor da Companhia do Mucuri, em sua Notícia..., Ottoni privilegiou três elementos para análise: as características e os costumes dos nativos; o choque entre os indígenas e a população em processo de expansão das fronteiras; e as estratégias adotadas pelo idealizador da Companhia do Mucuri para conquistar o apoio dos caciques.

\section{Violência nos Sertões das Minas e o tráfico de kurucas}

O conflito generalizado entre índios e conquistadores narrado por Teófilo Ottoni na Notícia... reforçou a acepção de Manuela Carneiro da Cunha sobre a "questão indígena no século XIX. Para Cunha, o item fundamental que envolveu os indígenas no oitocentos deixaria de ser uma questão de mão-de-obra para se converter principalmente em uma questão de terras. Segundo a autora, esta generalização sobre a questão indígena no oitocentos foi possível porque nesse período a tônica era a conquista do espaço nacional. Com isso, em regiões como Mato Grosso e no Paraná e até mesmo em Minas Gerais e Espírito Santo, as rotas fluviais a serem descobertas e consolidadas exigiam a submissão dos índios que nelas habitavam (CUNHA,1993:4). O domínio das rotas fluviais no Brasil oitocentista ganharia importância com a expansão da navegação à vapor e do progressivo dilatamento da fronteira em direção a regiões afastadas dos principais centros urbanos. 
Além de se tornar uma rota de navegação fluvial, o vale do Mucuri também deveria ser ocupado por colonos nacionais e estrangeiros, ocupados em comercializar seus produtos ao longo das estradas de rodagem construídas pela Companhia do Mucuri. Para tanto, era necessário estabelecer contato com várias tribos que habitavam a região, afamados em todo o Império do Brasil por sua hostilidade em estabelecer contatos com a população nacional. Preocupado com o modelo empregado no processo de dominação dos territórios indígenas, Ottoni enfatizou em memória publicada no periódico do IHGB que a forma de aldeamento a ser adotado no Mucuri não seria pautado na "doutrina da pólvora e da bala". Teófilo Ottoni acreditava que com um novo modelo de "catequese" seria mais fácil tomar posse das dez léguas em quadro doadas à Companhia a partir de um contrato celebrado com o governo central.

Segundo o relato de Ottoni, a região que a empresa deveria ser instalada encontravase em preocupante estado de violência: tribos indígenas que habitavam aqueles sertões assombravam os moradores instalados nas bordas da Mata Atlântica entre as províncias de Minas, da Bahia e do Espírito Santo. Em defesa de seu território contra o avanço dos colonizadores, a investida indígena contra a população que ocupava as margens da floresta tropical, provocava sucessivas depredações nas fazendas e contínuos assassinatos.

Diante do quadro de violência apresentado, Ottoni surpreendentemente concluiu que as sucessivas agressões dos índios eram resultado da agressão praticada pelos conquistadores do seu território. De acordo com o político liberal, "se de tempos em tempos ocorria algum atentado dos selvagens, era este mais das vezes filho, ou de sugestões criminosas dos chamados cristãos, ou do desespero que reagiam contra a brutalidade e tirania" (OTTONI, 1858:42).

Para o autor, os "atentados" cometidos pelos indígenas do Mucuri teriam sua origem na Carta Régia de $1808,{ }^{1}$ reportada como sendo de triste recordação, pois legalizava e estimulava a escravização das populações autóctones, declarando guerra de extermínio aos botocudo (OTTONI, 1858:45). Além disso, Ottoni justifica que o infame tráfico de crianças indígenas também justifica as depredações que os índios praticavam nas bordas da floresta tropical. ${ }^{2}$ É importante ressaltar que o tráfico de crianças indígenas (os kurucas) tornou-se uma

\footnotetext{
${ }^{1}$ Teófilo Ottoni se refere à Carta Régia expedida pelo príncipe regente D. João a Pedro Maria Xavier de Athayde e Mello, Governador e Capitão General da capitania de Minas Gerais. Datada de 13 de maio de 1808 a Carta Régia declarava estado de Guerra Justa aos índios botocudo.

${ }^{2}$ Os Kurucas eram crianças indígenas caçadas como presas para serem vendidas pelos invasores de suas terras. Embora a escravidão indígena tivesse sido condenada desde a aprovação do Diretório dos Índios em 1755, tal prática continuou durante o século XIX. No período analisado, segundo Warren Dean, um kuruca era 
prática largamente difundida entre os sertões das províncias de Minas Gerais, Espírito Santo e Bahia. Para Ottoni, a prática da escravidão de crianças indígenas ainda ganhava impulso com os sucessivos conflitos interétnicos entre nações indígenas rivais. Muitas vezes, a guerra entre diversas tribos tinha por único fim o tráfico dos kurucas para o trabalho escravo (CUNHA,1993:49). Um exemplo desta prática está na descrição feita por Ottoni da vila de São José de Porto Alegre, foz do rio Mucuri, província da Bahia. De acordo com o político liberal, em 1847 São José era uma aldeia miserável, cujo comércio se dava primordialmente da venda de crianças indígenas. Arrancadas de suas tribos de mil modos, cada criança indígena era vendida por 100 mil-réis (100\$000) em média (OTTONI: 1858:49-50). A documentação oficial expedida por órgãos da corte atestam a forma indiscriminada do tráfico de crianças indígenas nativas nos sertões do Mucuri. No Aviso expedido pelo Ministério do Império de 09 de agosto 1845, o Ministro José Carlos Pereira de Almeida Torres relata os abusos cometidos com a prática da venda de crianças:

Constando que, em algumas províncias, tem havido indivíduos que abusando da simplicidade dos Índios, lhes compram os filhos, e não só os conservam em perfeita escravidão, dando-lhes rigoroso trato, mas também os remetem vendidos, para esta corte, ou de umas províncias para outras ${ }^{3}$

O Aviso expedido por Almeida Torres solicita a todos os presidentes de província a adotarem "as mais enérgicas medidas" para por fim à continuação "de tão criminoso procedimento". Já o Aviso despachado pelo Ministério da Justiça em 2 de setembro de 1845 atestou a preocupação das autoridades com a venda de kurucas. O documento denuncia a chegada de uma jovem índia ingressa no Rio de Janeiro na lancha Senhora d'Ajuda. De acordo com o aviso, a nativa teria sido vendida como escrava em São Mateus, no Espírito Santo e enviada à corte para trabalhar na casa de "um tal" Francisco José Martins de Oliveira. Para prevenir a continuação de "tão escandaloso abuso", o documento ordena ao juiz de órfãos da Corte que todo indígena ingresso submetido a trabalho escravo - devido à sua "natural simplicidade" - deveria ser remetido à sua tribo de origem. ${ }^{4}$

Sobre o tráfico de crianças indígenas, Teófilo Ottoni posiciona-se radicalmente contra, ao ressaltar que esse tráfico, reputado pelo político como maldito, era mais hediondo e

comercializado a 100 mil-réis, enquanto um escravo africano era comprado a valor seis vezes mais caro. $C f$.: (DEAN, 1996: 169).

${ }^{3}$ Ministério do Império. Aviso - Sobre a compra dos filhos dos índios. 09 de agosto de 1845. In.: (CUNHA, 1993:199).

${ }^{4}$ Ministério da Justiça. Avisos - Sobre o trabalho dos índios em casas de particulares e outras providências. 02 de setembro de 1845. In: (CUNHA, 1993: 200-202). 
infame do que o praticado na África. Segundo Ottoni, era essa a causa de calamidades sem número presenciadas no vale do rio Mucuri (OTTONI, 1858: 49). Na Notícia..., encontra-se em detalhe a forma pela qual as crianças nativas eram subtraídas de suas famílias. O modelo adotado era o mais lastimável. Daí a importância dada pelo político liberal em descrever a forma usada para se apresar os kurucas.

Para o político liberal, a conquista da região do Mucuri transformou a área em um açougue, não em um lugar de combate. Isso se deve ao método que Teófilo definiu de capivara. Segundo Regina Horta Duarte, o nome é uma alusão à caça feita ao roedor homônimo (DUARTE, 2002: 46). Este método consistia-se numa estratégia utilizada pelos invasores para aniquilar tribos inteiras. Preocupado em detalhar como era feita a capivara, Ottoni descreveu minuciosamente como se procede esta técnica de dizimação de tribos indígenas. O modo de combate contra as populações nativas, segundo o político liberal, produzia uma verdadeira "hecatombe de selvagens":

\footnotetext{
Matar uma aldeia! Não passe a linguagem desapercebida. Por mais horrorosa que pareça nada tem de hiperbólica. É uma frase técnica na gíria da caçada dos selvagens Cerca-se a aldeia de noite - dá-se o assalto de madrugada. É de regra que o primeiro bote seja apoderarem-se os assaltantes dos arcos e flechas dos sitiados que estão amontoados no fogo que faz cada família. [...]

Os srs. Cro e Crahy entendem perfeitamente a metonímia, e recebido o convite, tratam de fazer a empreitada à satisfação que lha encomenda.

Procede-se a matança.

Separados os kurucas, e alguma índia moça mais bonita, que formam os despojos, sem misericórdia faz-se mão baixa sobre os outros, e os matadores não sentem outra emoção que não seja a do carrasco quando corre o laço no pescoço dos enforcados (OTTONI, 1858:47).
}

A região concedida pelo governo central à Companhia do Mucuri passava por um processo de turbulência que impedia que se consolidassem os planos da empresa. A dizimação das populações autóctones; o tráfico dos kurucas; as guerras interétnicas entre nações indígenas rivais; e os sucessivos ataques dos nativos às fazendas situadas na borda da Mata Atlântica, pintavam a história da região com tons funestos. Neste quadro de violência generalizada, o projeto da Companhia do Mucuri se via atravancado, pois como já mencionamos, era necessário conquistar dos índios a permissão para ocupar as terras concedidas pela administração imperial. Qual seria a solução encontrada por Teófilo Ottoni para cooptar o apoio dos índios e, assim, instalar a Companhia do Mucuri no interior da selva tropical?

\section{A administração provincial, os coadjuvantes e a conquista do Mucuri}


Ao observar in loco o estado de turbulência em que se encontrava o vale do rio Mucuri, Teófilo Ottoni convenceu-se de que os ataques dos nativos eram resultado dos ataques praticados pelos próprios "cristãos". A partir dessa dedução, o idealizador da companhia começou a traçar um novo método para conseguir dos nativos o apoio necessário à instalação da empresa:

[Eu] acreditava que um sistema de generosidade, moderação e brandura não podia deixar de captar-lhes a benevolência.

A principal dificuldade para a execução, ou ao menos ensaio deste sistema, estava em chamar à prática e convivência os filhos da selva, e em convencê-los de que havia com efeito um novo processo de catequese que não empregava a pólvora e a bala, nem tinha por objetivo roubar-lhes os filhos (OTTONI, 1858: 51).

Vislumbrando conquistar a confiança dos nativos, Teófilo Ottoni chefiou a expedição de setembro de 1847, responsável por adentrar no interior da floresta que guardava o vale do Mucuri. A primeira frente expedicionária partiu do Rio de Janeiro no vapor Princesa Imperial; a segunda foi organizada pelos principais fazendeiros do Termo de Minas Novas, como Feliciano Lopes da Silva. A expedição contava ainda com o fundamental apoio do governo provincial mineiro. Atendendo a um ofício de Teófilo Ottoni, o presidente de província Quintiliano José da Silva ordenou que fosse deslocada para o Mucuri, uma tropa de soldados da Companhia de Pedestres do Jequitinhonha para auxiliar os trabalhos das duas frentes expedicionárias. ${ }^{5}$

No que tange aos personagens envolvidos na conquista do vale do Mucuri, a Notícia... também é reveladora. Nela é possível identificar uma série de indivíduos que auxiliaram Teófilo Ottoni no projeto da empresa. Entre esses indivíduos podemos citar duas figuras que contribuíram de formas distintas e decisivas para a instalação da companhia no interior da Mata Atlântica. Aqui nos referimos ao já citado Quintiliano José da Silva e ao fazendeiro Luiz Ferreira da Gama.

Presidindo a província de Minas entre 1845 e 1847 Quintiliano José da Silva mostrouse um entusiasta do projeto de ocupação do vale do Mucuri. Quintiliano foi um dos principais entusiastas da navegação do rio Mucuri, ressaltando a relevância dessa região para o

\footnotetext{
${ }^{5}$ Além das forças policiais e da Guarda Nacional, a província de Minas Gerais contava ainda com os auxílios dos Soldados Pedestres. Distribuídos em duas companhias distintas, a do Rio Doce e a do Jequitinhonha, este grupamento militar era responsável em guarnecer os locais de ocupação recente nas regiões limítrofes ao chamado Sertão do Leste, sobretudo nos limites das comarcas do Serro Frio e Jequitinhonha. Quintiliano José da Silva. Fala dirigida à Assembléia Legislativa Provincial de Minas Gerais na sessão ordinária de 1847. Ouro Preto: Tipografia Imparcial de B. X. Pinto de Sousa, 1847. p. 28.
} 
desenvolvimento da "importante" Comarca do Jequitinhonha. ${ }^{6}$ É necessário notar também que o projeto de conquista do Mucuri foi favorecido pela relativa longevidade da administração de Quintiliano, cerca de três anos. Caracterizados por administrações efêmeras, os governantes provinciais tinham dificuldades em dar prosseguimento aos projetos, devido às constantes mudanças na cadeira da presidência. Esta característica da política imperial foi assunto criticado pelos próprios presidentes de província. Nos relatórios apresentados à assembléia provincial, encontravam-se várias queixas sobre os males que a transitoriedade dos governos causava à administração pública. ${ }^{7}$ Conforme apontou Francisco Iglésias,

[...] com tempos tão exíguos, tornava-se impossível administrar. O presidente mal chegava e sabia que não tinha muitos meses para permanecer. Essa certeza já era suficiente para aniquilar qualquer propósito realizador. Ainda que a autoridade vencesse o embaraço e se dispusesse ao trabalho, mal começando a atividade viria a remoção para outra província, ou chegava o tempo de assumir o posto na Câmara ou no Senado (IGLÉSIAS, 1958:43-45).

Beneficiado pela relativa estabilidade em seu cargo como presidente provincial, os esforços de Quintiliano para ocupar o vale do Mucuri foram mais constantes do que a experiência esboçada anteriormente pela administração do presidente Costa Pinto. Entre os referidos esforços encontram-se o contrato celebrado com três capuchinhos italianos para atuarem na catequese do gentio que "infestava" o Mucuri. Segundo o relatório da presidência provincial de 1847, o Aviso de 23 de agosto de 1846, emitido pela Secretaria dos Negócios do Império, colocava à disposição do presidente da província de Minas os serviços de catequese dos capuchinhos italianos Luís de Revena, Domingos Casale e Bernardino de Lago Negro. Em 1847, o presidente deu notícias sobre os clérigos contratados pela província de Minas: o primeiro, Luís de Revena, achava-se doente na cidade de Campanha "em uso das águas virtuosas". O segundo, Domingos Casale já se encontrava a caminho do interior do vale do Mucuri e o terceiro, frei Lago Negro, encontrava-se no Seminário de Mariana, aprendendo o idioma nacional para depois seguir para os sertões do Mucuri. ${ }^{8}$

Se o auxílio administrativo do presidente de província Quintiliano José da Silva foi fundamental para consolidar o empreendimento da Companhia do Mucuri, não menos

\footnotetext{
${ }^{6}$ Fala dirigida à Assembléia Legislativa Provincial de Minas Gerais na sessão ordinária de 1847. Ouro Preto: Tipografia Imparcial de B. X. Pinto de Sousa, 1847. p. 45-46.

${ }^{7}$ Em boa parte dos relatórios apresentados à Assembléia Provincial as queixas são uníssonas em relação à falta de tempo para se tomar conhecimento dos problemas provinciais. A província de Minas, por exemplo, possuiu 122 períodos administrativos e 59 presidentes. Esse número perfaz uma média de 6 meses e 22 dias para cada presidente de província.

${ }^{8}$ Quintiliano José da Silva. Fala dirigida à Assembléia Legislativa Provincial de Minas Gerais na sessão ordinária de 1847. Ouro Preto: Tipografia Imparcial de B. X. Pinto de Sousa, 1847. p. 89.
} 
importante foi a atuação do fazendeiro Luiz Ferreira da Gama. Pouco se sabe sobre esta personagem. Na lista de emigrados fornecida pelo Instituto Histórico da Ilha Terceira - região dos Açores - aparece um homônimo que emigrou para o Rio de Janeiro em 1812. ${ }^{9}$ Contudo, não podemos afirmar que o homônimo em questão seja o nosso Luiz Ferreira da Gama.

Segundo a Notícia... Luiz Ferreira da Gama e sua família são apresentados como os fazendeiros que habitavam a mais remota parte do vale do Mucuri. Segundo Teófilo Ottoni, por ter conquistado a amizade dos temidos índios jiporocks, Gama "vivia tranquilo no centro das matas com sua família" (OTTONI, 2002:52). De acordo com Teófilo Ottoni, teria sido Luiz Ferreira da Gama quem proporcionou o primeiro contato do idealizador da Companhia com os índios botocudo. Gozando da confiança adquirida com os nativos, o fazendeiro procurou aglomerar um grupo de botocudo em torno de sua casa para receberem miçangas, espelhos e ferramentas. ${ }^{10}$ Após reunir os nativos, Gama instruiu Teófilo Ottoni e o Vigário geral de Caravelas, Norberto da Costa e Souza, a repartir a cada indivíduo o seu quinhão de "presentes" (OTTONI, 1858: 53-54).

Desse modo, como já dissemos, deve-se a Luiz Ferreira da Gama a realização do “contato" entre Teófilo Ottoni e os "selvagens do Mucuri”. A partir deste contato, Ottoni diz ter captado a "amizade" da nação jiporock, que passou a chamá-lo de Capitão Grande. No desfecho do primeiro encontro com a nação jiporock, conforme é narrado pelo político liberal ocorreu um fato pitoresco. O cacique da tribo ofereceu ao "Capitão Grande", como forma de reconhecimento pela "amizade", um casal de kurucas.

Desse acontecimento, Ottoni aproveitou para demonstrar aos leitores da Notícia... como ele se posicionou corretamente diante do inusitado fato. Segundo o relato publicado na revista do IHGB, o índio que havia "ganhado" foi enviado para o Rio de Janeiro, onde foi admitido como aprendiz do Arsenal de Guerra da Marinha, a fim de ser convertido em “instrumento da civilização dos seus patrícios e parentes”. De acordo com o autor da Notícia..., o jovem índio faleceu tempos depois (OTTONI, 1858:53-54) provavelmente por conta de alguma doença contagiosa.

\footnotetext{
9 Instituto Histórico da Ilha Terceira. Lista dos Emigrados das Ilhas dos Açores para o Brasil. Disponível em: http://www.ihit.pt/new/emigranteslistar.php. Acessado em 27 de fevereiro de 2008.

${ }^{10}$ De acordo com Livro de Caixa da Companhia do Mucuri, "os presentes" custaram ao todo 500 mil-réis (500\$000) e foram adquiridas no Rio de Janeiro com o intermédio da já mencionada empresa Ottoni \& Cia. Arquivo Público Mineiro (APM). Fundo Secretaria de Governo, 32. Livro de Caixa da Companhia de Navegação e Comércio do Mucuri. p.6
} 
Além do jovem índio, Ottoni também foi "presenteado" com uma índia. Em seu relato sobre os "selvagens do Mucuri", o político liberal descreve a doação da índia relembrando o episódio da mitologia grega em que Agamenon vai ao sacrifício de sua filha, Ifigênia:

\footnotetext{
Um outro, novo Agamenon, trouxe para o sacrifício a sua pobre Ifigênia, e mandouma por intermédio da família Gama, dizendo que fazia aquele donativo para eu ficar manso.

Despediu-se da menina chorosa, mas ao mesmo tempo consolava dizendo-lhe que ela ia ganhar muitas coisas bonitas.

Felizmente e em ato sucessivo a minha canoa aportou à casa de Gama a tempo de poder eu restituir a Ifigênia a Agamenon, tranqüilizando-o sobre as atuais disposições dos cristãos.

E foi a Ifigênia dos Jiporoks mais feliz que a dos gregos (OTTONI, 1858, 53-54).
}

Além da viagem feita em 1847, outra foi organizada para estabelecer contatos com novas tribos botocudo. O objetivo da expedição realizada em 1852 seria o mesmo da realizada cinco anos antes: tomar posse das terras concedidas pelo governo central à Companhia do Mucuri.

Mais uma vez, a estratégia utilizada por Teófilo Ottoni não seria diferente do costumeiramente praticado por ele para estabelecer contato com os índios, daí a distribuição dos "presentes" aos nativos: "Logo que descobria uma batida de selvagens, mandava dependurar nas árvores, em lugar bem visível para quem passasse diversos presentes, ora uma foice, ora um machado" (OTTONI, 1858, 61).

Contudo, a estratégia de Ottoni apresentou um elemento que chamava atenção para um detalhe. Nas ferramentas colocadas sobre o galho das árvores, o político liberal mandava que fosse colocado o seu cartão de visita impresso no Rio de Janeiro: “[...] colocava no olho do machado, ou alvado da foice meu cartão de visita, esperando captar a benevolência com o presente, e com o cartão que certo não decifrariam, desafiar o sentimento do maravilhoso. Foi com este mesmo estratagema que o político liberal conseguiu estabelecer os primeiros contatos com a igualmente temida tribo dos naknenuks. A nova expedição também foi composta por duas frentes expedicionárias. A primeira partiu da região do Alto dos Bois e foi chefiada pelos fazendeiros Manoel Esteves Ottoni, Augusto Benedito Ottoni, Silvério José da Costa e Casimiro Gomes Leal. A segunda, chefiada por Teófilo Ottoni partiu da região de Santa Clara.

\section{Teófilo Ottoni e os índios do Mucuri}


No interior de uma das regiões mais afastadas dos núcleos de colonização, Teófilo Ottoni conseguiu "fazer conferências" com os caciques Poton, Batata e Timóteo, todos da nação naknenuk. Mais uma vez, a estratégia descrita por Ottoni em sua Notícia... surpreendeu novamente o leitor pelo detalhe. Eis o estratagema do político liberal:

De Poton me declarei parente, e ele acolheu rindo a demonstração de que éramos. Tirei a demonstração do nome - Poton - que pronunciei - Potoni - e do qual, não sei porque regra de etimologia, extraí - Ottoni.

Aceito o parentesco, disse-me Poton que trouxesse os mais parentes, porque as terras eram muitas e chegavam para todos.

Peguei-lhe pela palavra, e 15 dias depois abria-se por conta de diversos parentes do selvagem uma grande derrubada, que produziu três magníficas fazendas (OTTONI, $1858,62)$.

A atuação de Ottoni na empreitada de conquistar das populações autóctones a permissão para a posse das terras cedidas à Companhia do Mucuri rendeu-lhe grande prestígio político (veja fig. 1). Dos naknenuks Ottoni ganhou a alcunha de Pogirun, que significa Capitão de Mãos Brancas. Ao que parece, o nome Pogirum ganhou fama na corte. Na charge de Henrique Fleiuss, publicada na revista Semana Ilustrada em 1866 há uma representação que caracteriza a intensa atuação política de Teófilo Ottoni.

No que se refere ao trato com os nativos, a prática adotada por Ottoni chamava a atenção por se aproximar do que havia preconizado o estadista José Bonifácio de Andrada e Silva e o sertanista francês Guido Marlière. Em 1916, no preâmbulo publicado para a segunda edição da Circular de 1860, Basílio de Magalhães ressaltou que o "trato diferenciado" dado por Ottoni aos indígenas foi fundamental para atrair "os desgraçados aborígines" para a civilização, e, com isso, integrá-los definitivamente à "grande Pátria". Ao expor a experiência do político liberal com os índios botocudo, Magalhães comparou a atuação de Ottoni com o projeto anteriormente esboçado por José Bonifácio, a quem Magalhães reportou como “incomparável estadista" (MAGALHÃES: 1916: 168).

Em seus Apontamentos para Civilização dos Índios Bravos do Império do Brasil [1823], Bonifácio chamou a atenção para alguns métodos "mais eficazes" para a integração dos nativos ao Estado nacional (ANDRADA, 1823:126). Contudo, o próprio Bonifácio já lamentava a forma pela qual os índios eram captados pela sociedade brasileira. Segundo o estadista, na relação estabelecida com os nativos, "a sociedade nacional mostrava apenas os seus vícios e fraquezas, sem comunicar nenhuma de suas virtudes e talentos" (ANDRADA, 1823:126). Para o "Patrono da Independência do Brasil", os benefícios legais que os índios 
deveriam gozar eram pura ilusão, pois "a pobreza que se acham, a ignorância por falta de educação e as vexações dos diretores e capitães os tornam abjetos e mais desprezíveis que os mulatos forros" (ANDRADA, 1823:126).

Se levarmos em consideração que durante boa parte do século XIX a figura do índio era pintada pela ideia da bestialidade, da fereza e da animalidade, ao menos o projeto de "pacificação" idealizado por Teófilo Ottoni, mostrou-se diametralmente oposto ao do usualmente praticado. ${ }^{11}$ Ora, até os anos 60 do século XIX a discussão se travava não em torno dos fins de uma política indigenista, mas sim em torno dos seus meios: se se deviam exterminar sumariamente os índios; distribuí-los aos moradores - conforme concebia o projeto de José da Silva Lisboa, visconde de Cairu -; ou se deviam cativa-los com brandura (CUNHA, 1993:5).

Um exemplo inequívoco da forma pela qual os índios botocudo eram concebidos pela sociedade oitocentista pode ser encontrado na obra do médico alemão Robert Avé-Lallemant. No livro Viagens pelas províncias da Bahia, Pernambuco, Alagoas e Sergipe, Lallemant adentrou o interior de Minas Gerais para conhecer o projeto da Companhia do Mucuri. Do encontro com os botocudo surgiu uma peça que chamaria a atenção pelo teor de escárnio e de repulsa em relação aos "selvagens do Mucuri".

As impressões racialistas do médico alemão sobre os botocudo também eram reveladoras na tentativa de se traçar um paralelo entre o projeto de ocupação proposto por Teófilo Ottoni e a concepção difundida sobre os índios do vale do Mucuri. Influenciado pelas teorias racialistas em voga na Europa, Lallemant descreveu seu encontro com os botocudo como sendo a experiência mais estranha que já havia tido com grupos humanos. Eis o que diz o médico alemão sobre a mulher botocudo:

Sem nenhuma expressão feminina no rosto, baixas e gordas, postavam-se ali, com um sorriso meio imbecil [...]. As caras idiotas, os botoques em constantes movimentos para baixo e para cima, as mamas bambaleantes, a completa nudez das mulheres [...], as grandes cicatrizes nas espáduas e nas costas, resultantes do tratamento brutal dos homens, os pulinhos desajeitados - tudo isso causa uma impressão tão verdadeiramente horrível, que não posso traduzi-la em palavras. O leitor sentirá com certeza, sem que eu precise dizer mais (LALLEMANT, 1858:243).

\footnotetext{
${ }^{11}$ Esta imagem pode ser demonstrada na resposta de um administrador provincial mineiro. Em 1827, ao ser indagado pelo Visconde de São Leopoldo sobre a índole dos botocudo, o presidente da província de Minas Gerais, Francisco Pereira de Santa Apolônia, respondeu nos seguintes termos: "Permita-me que V. Exa . refletir que de tigres só nascem tigres; de leões, leões se geram; e dos cruéis botocudos (que devoram e bebem o sangue humano) só pode resultar prole semelhante". Apud., (CUNHA, 1993:5).
} 
A repugnância de Lallemant em relação aos índios do vale do Mucuri demonstrava que também entre os intelectuais, persistia a ideia da impossibilidade desses indígenas serem úteis aos desígnios da civilização. ${ }^{12}$ Se tomarmos esta proposição como verdadeira, Teófilo Ottoni, ao oferecer aos índios do vale do Mucuri um novo modelo de colonização, demonstraria que as ideias difundidas sobre a população nativa eram falaciosas e impregnadas de preconceito. De acordo com o trabalho de Valdei Araujo, é nos quadros do jusnaturalismo e no chamado reformismo ilustrado, aos moldes do século XVIII, que Ottoni irá compreender os costumes indígenas. Por trás da diferença, do exótico, ele tentará perceber a natureza humana, isto é, tentará perceber os valores da razão que permanecem intemporalmente (ARAUJO, 1998). Com um novo "método", Ottoni demonstrou ser possível conseguir o apoio dos nativos sem ter que os vitimar com toda sorte de agruras.

O modelo de colonização realizado por Ottoni chamou a atenção do brazilianist Warren Dean. Este autor destacou que a empreitada colonizadora de Teófilo Ottoni teria sido a primeira em toda a história do Brasil a não fazer uso da força para conquistar o contato com os nativos. Pela primeira vez foi ordenado aos batedores militares que não atirassem nos indígenas, ainda que estes atacassem com suas flechas (DEAN, 1996:164).

\section{Conclusão}

A experiência colonizadora do vale do rio Mucuri representou em sua época uma nova forma de cooptação dos nativos. Conforme deixou registrado em seus discursos, Ottoni a classificou de "catequese conscienciosa". ${ }^{13}$ As tribos que durante toda a década de 1840 assombravam os moradores de Minas Gerais, da Bahia e do Espírito Santo aceitaram serem instalados em aldeamentos próximos aos futuros núcleos de colonização da Companhia do Mucuri. Ao captar o "apoio" dos índios, finalmente o político liberal pôde tomar posse das terras concedidas ao seu empreendimento. Agora o Projeto Mucuri poderia intensificar o processo de ocupação da floresta tropical e dar cabo ao audacioso processo de ocupação dos sertões de Minas Gerais Imperial. Dos discursos produzidos sobre o processo de ocupação dos

\footnotetext{
${ }^{12}$ De acordo com Ernest Gellner, o Estado-nação não tolerou a proliferação de subculturas internas, daí a empreitada da difusão dos ideais da chamada "cultura superior". No caso do Estado nacional português, desde o chamado Diretório Pombalino [1755] já estava previsto na legislação que os índios deveriam se tornar "úteis" ao Estado. Desse modo, a lei instituía que todos eles deveriam ser declarados livres e vassalos do rei. Sobre a tentativa de homogeneização da "cultura superior" por parte do Estado-nação, $C f:$ : (GELNER, 2000:107-174).

${ }^{13}$ Documentos Anexos ao Relatório que à Assembléia Legislativa Provincial de Minas Gerais apresentou na sessão ordinária de 1854 o presidente da província Francisco Diogo Pereira de Vasconcelos. Ouro Preto: Tipografia do Bom Senso, 1854. p. 8.
} 
sertões mineiros emerge novamente a velha contradição entre a retórica e a prática no trato com os nativos no Brasil Oitocentista. Se por um lado a imagem do índio estava sendo alçada à categoria de símbolo romântico nos discursos que buscavam forjar uma identidade nacional, na prática isso em nada contribuiu para os proteger de toda sorte de exploração e ultrajes. Ainda que a legislação os protegessem, a Notícia Sobre os Selvagens do Mucuri sugere que estas medidas não passavam de letra morta.

\section{Fontes}

Arquivo Público Mineiro (APM). Fundo Secretaria de Governo, 32. Livro de Caixa da Companhia de Navegação e Comércio do Mucuri.

MINISTÉRIO do Império. Aviso - Sobre a compra dos filhos dos índios. 09 de agosto de 1845. In.: CUNHA, Manuela Carneiro da(org.). Legislação Indigenista no século XIX. São Paulo: Edusp; Comissão Pró-índio, 1993.p. 199.

MINISTÉRIO da Justiça. Avisos - Sobre o trabalho dos índios em casas de particulares e outras providências. CUNHA, Manuela Carneiro da(org.). Legislação Indigenista no século XIX. São Paulo: Edusp; Comissão Próíndio, 1993. p. 200-202.

CARTA Régia de 13 de maio de 1808 expedida por D. João, príncipe regente, a Pedro Maria Xavier de Athayde e Mello, Governador e Capitão General da Capitania de Minas Gerais. CUNHA, Manuela Carneiro da(org.). Legislação Indigenista no século XIX. São Paulo: Edusp; Comissão Pró-índio, 1993. p. 57-60.

CHARGE de Henrique Fleiuss. Semana Ilustrada, no 302, 23 de setembro de 1866. Apud. Paulo Pinheiro Chagas. Teófilo Ottoni: ministro do povo. Belo Horizonte: Itatiaia; Brasília: INL, 1978.

Instituto Histórico da Ilha Terceira (IHIT). Lista dos Emigrados das Ilhas dos Açores para o Brasil. Disponível em: http://www.ihit.pt/new/emigranteslistar.php. Acessado em 27 de fevereiro de 2008.

LISBOA, José da Silva. Memória sobre a civilização dos índios e distribuição das matas oferecida à Sagrada Pessoa d'El Rei Nosso Senhor. In: CUNHA, Manuela Carneiro da (org.). Legislação Indigenista no século XIX. São Paulo: Edusp; Comissão Pró-índio, 1993. p.17.

SILVA, José Bonifácio de Andrada e. "Apontamentos para Civilização dos Índios Bravos do Império do Brasil" [1823]. In: Projetos Para o Brasil. Mirian Dolhnikoff (org.) São Paulo: Companhia das Letras, 1998.

SILVA, Quintiliano José da. Fala dirigida à Assembléia Legislativa Provincial de Minas Gerais na sessão ordinária de 1847. Ouro Preto: Tipografia Imparcial de B. X. Pinto de Sousa, 1847.

OTONI, Teófilo. Notícia Sobre os Selvagens do Mucuri. Organização: DUARTE, Regina Horta. Belo Horizonte: Editora UFMG, 2002.

VASCONCELOS, Francisco Diogo Pereira de. Relatório Provincial de 1854. Ouro Preto: Tipografia do Bom Senso, 1854.

\section{Referências Bibliográficas}

ARAUJO, Valdei Lopes de. A experiência do tempo: conceitos e narrativas na formação nacional brasileira (18131845). São Paulo: Hucitec, 2008.

ARAUJO, Valdei Lopes de. Teófilo Benedito Ottoni: política, historiografia e esfera pública no Brasil oitocentista. Rio de Janeiro: Uerj. 1998. (Dissertação de Mestrado).

CUNHA, Manuela Carneiro da (org.). Legislação Indigenista no século XIX. São Paulo: Edusp; Comissão Próíndio, 1993. 
DEAN, Warren. A ferro e Fogo: a história da devastação da mata atlântica brasileira. São Paulo: Companhia das Letras, 1996.

DUARTE, Regina Horta. "Conquista e Civilização na Minas Oitocentista”. In: Teófilo Benedito Ottoni. Notícia Sobre os Selvagens do Mucuri. Org: Regina Horta Duarte. Belo Horizonte: Editora da UFMG, 2002.

FERREIRA, Laís Ottoni Barbosa. Os Ottoni: descendentes e colaterais. Rio de Janeiro: L.O.B. Ottoni, 1998.

GELLNER, Ernest. "Advento do nacionalismo e sua interpretação: os mitos da nação e da classe". In.: BALAKRISHNAN, Gopal (Org.). Um Mapa da Questão Nacional. Rio de Janeiro: Contraponto, 2000. p. 107154.

GUIMARÃES, Manoel Salgado. "Nação e Civilização nos Trópicos: o Instituto Histórico e Geográfico Brasileiro e o projeto de uma história nacional”, Estudos Históricos, Rio de Janeiro, n. 1, 1988. p. 5-37.

IGLÉSIAS, Francisco Iglésias. Política Econômica do Governo Provincial Mineiro (1834-1889). Rio de Janeiro: Ministério da Educação e Cultura, 1958.

MAGALHÃES, Basílio. "A Circular de Theophilo Ottoni”. In: Revista do Instituto Histórico e Geográfico Brasileiro. Tomo LXXVIII, Parte 2. Rio de Janeiro: 1916.

MATTOS, Izabel Missagia de. Civilização e Revolta: os botocudos e a catequese na província de Minas. Campinas: Unicamp, 2002. (Tese de Doutorado). 